\title{
TRANSPLANTATION OF SCAFFOLD-FREE SPHEROIDS COMPOSED OF SYNOVIUM-DERIVED CELLS AND CHONDROCYTES FOR THE TREATMENT OF CARTILAGE DEFECTS OF THE KNEE
}

\author{
J.-I. Lee ${ }^{1}$, M. Sato ${ }^{2, *}$, H.-W. Kim ${ }^{1}$ and J. Mochida ${ }^{2}$
}

\begin{abstract}
${ }^{1}$ Regenerative Medicine Laboratory, Centre for Stem Cell Research, Department of Biomedical Science and Technology, SMART Institute of Advanced Biomedical Science, Konkuk University, Seoul, Korea

${ }^{2}$ Department of Orthopaedic Surgery, Surgical Science, Tokai University School of Medicine, Kanagawa, Japan
\end{abstract}

\begin{abstract}
Autologous chondrocyte implantation (ACI) is the treatment of choice for osteoarthritis. However, to regenerate articular cartilage using this method, the procedure paradoxically demands that the cell source of the articular chondrocytes (ACs) for ex vivo expansion be from the patient's own healthy cartilage, which can result in donor site morbidity. Accordingly, it is essential to develop a substitute for AC. In the present study, we investigated whether synovium-derived cells (SYs) could be used as a partial replacement for ACs in ACI. ACs and SYs from the knees of rabbits were isolated and cultured, and the growth rates of the cells were compared. To manufacture the cellular transplants, we developed a high-density suspension-shaking culture method (HDSS), which circulates the cells in culture media, promoting self-assembly of scaffold-free cellular aggregates. ACs and SYs were mixed in various ratios using HDSS. Injectable cellular transplants were harvested and transplanted into full-thickness osteochondral defects. Simultaneously, histological evaluations were conducted with toluidine blue and safranin $\mathrm{O}$, and immunohistochemistry of collagen type I and II was conducted. Gene expression to evaluate chondrocyte-specific differentiation was also performed. We successfully prepared a large quantity of spheroids (spheroidal cell aggregates) in a short time using mixed ACs and SYs, for all cellular composition ratios. Our data showed that the minimal therapeutic unit for the transplants contributed to in situ regeneration of cartilage. In summary, SYs can be used as a replacement for ACs in clinical cases of ACI in patients with broad areas of osteoarthritic lesions.
\end{abstract}

Keywords: Articular cartilage regeneration, injectable scaffold-free spheroids, high density suspension shaking culture method, synovium-derived cells, chondrocytes.

*Address for correspondence:

Masato Sato

Department of Orthopaedic Surgery, Surgical Science, Tokai University School of Medicine,

143 Shimokasuya, Isehara, Kanagawa, 259-1193 Japan

Telephone Number: +81-463-93-1121 (ext 2320)

FAX Number: + 81-463-96-4404

E-mail: sato-m@is.icc.u-tokai.ac.jp

\section{Introduction}

Adult articular cartilage has a limited capacity for selfrepair after either degeneration or injury occurs and is therefore unlikely to be restored to normal once it has been damaged.

Autologous chondrocyte implantation (ACI), first reported by Brittberg group (Brittberg et al., 1994), has been used clinically. Promising results for transplantation of cultured autologous cartilage cells have been reported, and various articular cartilage regeneration techniques have been clinically applied, including the use of scaffolds such as atelocollagen (Ochi et al., 2002) and cell transplantation therapy with articular chondrocytes, synovium-derived cells (Shimomura et al., 2010), and bone marrow-derived mesenchymal stem cells (Wakitani et al., 2002). In addition, tissue-engineered cartilage with varying scaffold materials (Buckwalter and Mankin, 1998; Freed et al., 1994; Ochi et al., 2001; Darling and Athanasiou, 2003) or without scaffolds (Brehm et al., 2006; Nagai et al., 2008a; Nagai et al., 2008b; Mitani et al., 2009) have been developed and introduced.

While clinical results have shown that ACI can be beneficial, problems remain, such as periosteal hypertrophy, limits on the size of lesions that can be treated due to associated donor site morbidity, ability to treat only a predetermined defect area, alterations in the chondrogenic phenotype associated with in vitro expansion of the cells, and lengthened ex vivo culturing time for preparing a large amount of articular chondrocytes (ACs). In addition, due to alterations and degenerative changes in cartilage accompanying aging, the availability of such cells may be limited in elderly patients (Nehrer $e t$ al., 2006; Iwasa et al., 2009).

To overcome these issues, therapies using stem cells have been studied to facilitate tissue repair. Recently, research has focused on synovium-derived cells (SYs), whose high proliferative potency does not change with age, associated with mesenchymal stem cells (MSCs) that have the capacity to differentiate into chondrocytes. SYs of MSCs have the capability to proliferate and differentiate into a variety of connective tissue cells (De Bari et al., 2001). ACs from aged patients show limited proliferation in vitro; in contrast, MSCs are an attractive cell source for cartilage regenerative medicine because they can be harvested in a minimally invasive manner, are easily isolated and expanded, and have multipotentiality that includes chondrogenesis ( Prockop, 1997; Pittenger et al., 1999; Sekiya et al., 2002; Sakaguchi et al., 2005). In addition, synovial MSCs are especially promising due to 
their high proliferative capacity and chondrogenic potential ( Sakaguchi et al., 2005; Mochizuki et al., 2006; Yoshimura et al., 2007; Nagase et al., 2008; Nimura et al., 2008).

As disadvantages of pure cell suspension delivery were identified in several previous studies, artificial scaffolds have been adopted to deliver cells into cartilage-defect sites and to reinforce the mechanical stability of threedimensional (3D) tissue-engineered chondral grafts. An ideal scaffold would encourage the development of the extracellular matrix (ECM). Although a few scaffolds have been applied successfully to cartilage regeneration (Masuoka et al., 2005), challenges remain regarding biocompatibility and cellular viability, including cell attachment, distribution, and proliferation (Mitani et al., 2009). Biological or synthetic materials can cause immunological problems such as acute rejection, foreign body reaction, or fibroblastic overgrowth (Anderson et al., 2008; Badylak and Gilbert, 2008), which have an impact on the therapeutic effect.

Accordingly, we have developed 3D, scaffold-free, tissue-engineered cartilaginous tissues (Nagai et al., 2008a; Mitani et al., 2009) from chondrocytes and transplanted these tissues into the region of osteochondral defects as an initiator of cartilage differentiation in reparative cells (Kaneshiro et al., 2006; Nagai et al., 2008b); we achieved good long-term restoration results. However, the overall process of these methods requires a comparatively long period (more than 4 weeks), as reported previously for studies of ACI (Brittberg et al., 1994; Freed et al., 1994; Buckwalter and Mankin, 1998; Ochi et al., 2001; Ochi et al., 2002; Wakitani et al., 2002; Darling and Athanasiou, 2003; Brehm et al., 2006; Shimomura et al., 2010). Therefore, a shortened process for the preparation of ACI was accomplished using a high-density suspension-shaking (HDSS) culture method, which allows an equivalent amount of mass transfer to be achieved more quickly, thereby increasing the feasibility of this ACI using a new scaffold-free transplantation system. Conversely, as is well known, pellet culture is a representative 3D culture technique. A pellet culture system that allows cell-cell interactions, analogous to those that occur in pre-cartilage condensation during embryonic development, has been reported as a way to prevent and reverse the phenotypic modulations of chondrogenesis in vitro. Because this system forms only one aggregate, this aggregate cannot be used to produce tissue-engineered cartilage (Furukawa et al., 2003).

The purpose of this study was to evaluate the feasibility of a new method for scaffold-free spheroids (spheroidal cell aggregates) using an HDSS method originally devised to manufacture structures comprising two types of cells, and to investigate whether ACs and SYs form transplantable spheroids for cartilage regeneration in rabbits. To investigate the effects of implantation, we conducted animal experiments using these scaffold-free transplants. The recovered spheroids, which were constructed using different mixing ratios, were analysed histopathologically and morphologically, and a gene expression analysis was performed to test the cartilaginous phenotype. The results revealed that our HDSS culture system shortened the preparation time by half (less than 2 weeks) and produced a considerable amount of spheroids for ACI.

\section{Materials and Methods}

Animal experiments were approved and carried out following the Guidelines of Tokai University on Animal Use.

\section{Primary cultures of articular chondrocytes and synovium-derived cells}

With the rabbits under isoflurane (Forane ${ }^{\circledR}$; Abbott Japan, Tokyo, Japan) anaesthesia (induction $4 \%$, maintenance 2.0 $\%$ under $30 \%$ oxygen and $70 \%$ nitrous oxide), specimens of articular cartilage and synovium with subsynovial tissue were harvested from the knee joints of 4-week-old male Japanese white rabbits weighing approximately $1 \mathrm{~kg}$. The cartilage and synovial tissues were stored in basal medium (BM) containing Dulbecco's modified Eagle's medium/ F12 (DMEM/F12; Gibco/ Invitrogen, Carlsbad, CA, USA) supplemented with $10 \%$ heat-inactivated foetal bovine serum (FBS; Gibco/Invitrogen), $50 \mu \mathrm{g} / \mathrm{mL}$ ascorbic acid (Nissin Pharmaceutical Co, Yamagata, Japan), and $1 \%$ antibiotic-antimycotic mixture (ABAM; 10,000 U/mL penicillin $\mathrm{G}, 10,000 \mu \mathrm{g} / \mathrm{mL}$ streptomycin sulphate, and 25 $\mu \mathrm{g} / \mathrm{mL}$ amphotericin B as Fungizone; Gibco/Invitrogen) until required for the next step. The samples were cut using scissors with curved blades on a watch glass (120 mm diameter; Toshinriko Co., Tokyo, Japan). Thereafter, the finely chopped specimens were digested for 3-4 h in BM containing $0.5 \%$ collagenase (collagenase class I; Worthington Biochemical, Lakewood, NJ, USA).

The digested cell suspensions were passed through a cell strainer (BD Falcon ${ }^{\mathrm{TM}}$; BD Bioscience, Bedford, MA, USA) with a pore size of $70 \mu \mathrm{m}$, and the isolated cells were rinsed twice with chilled Dulbecco's phosphate-buffered saline (PBS; Dainippon Pharmaceutical, Osaka, Japan). The isolated primary cells were counted on a Burker-Turk haematocytometer (Erma, Tokyo, Japan) with trypan blue staining. The ACs and SYs were then each seeded into 500 $\mathrm{cm}^{2}$ dishes $(245 \times 245 \mathrm{~mm}$; Corning, Corning, NY, USA) at a density of 20,000 cells $/ \mathrm{cm}^{2}$ and cultured in BM with $10 \% \mathrm{FBS}$ at $37^{\circ} \mathrm{C}$ under an atmosphere of $5 \%$ humidified $\mathrm{CO}_{2}$ and $95 \%$ air according to previously reported methods for ACs of (Mitani et al., 2009) and for SYs of (Koga et al., 2007). The culture medium was changed twice a week. The cells were cultured until $90 \%$ confluence as passage 0 . At subconfluence, the seeded cells were expanded by sequential passages in monolayer cultures in BM with 10 $\%$ FBS. Each passage of AC and SY cells was detached using $0.05 \%$ trypsin/ethylene-diaminetetraacetic acid (EDTA; Gibco/Invitrogen) for $20-30 \mathrm{~min}$ at $37{ }^{\circ} \mathrm{C}$. The cells were centrifuged at $200 \mathrm{~g}$ for $5 \mathrm{~min}$. The washed pellet was resuspended in medium and the passages were subsequently reseeded under the same conditions described above. The cells were trypsinised and further expanded for passage. 


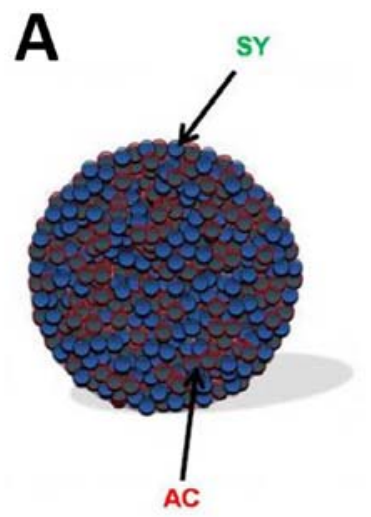

B

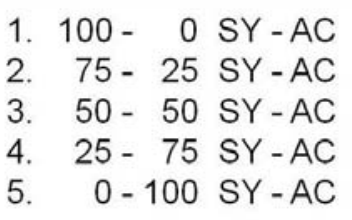

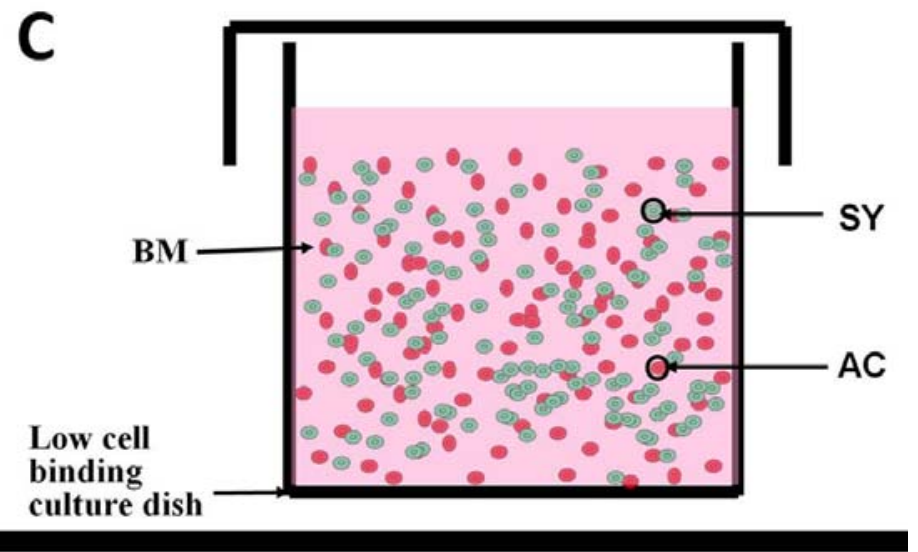

Rotary shaker

Fig. 1. Construction of scaffold-free spheroids. (A) Schematic illustration of the manufacture of scaffold-free spheroids. (B) Recovered ACs and SYs were mixed in various ratios and subjected to either morphological evaluation or gene expression analysis. In addition to the in vitro analyses, we selected the optimum ratio of ACs and SYs (2. 75:25 SY:AC) for in vivo implantation. (C) Schematic illustration of the high-density suspension-shaking culture method (HDSS). To fabricate the spheroids, a total of $1.0 \times 10^{7}$ cells $/ 5 \mathrm{~mL}$ medium was plated on each low cellbinding culture dish and the shaking culture was maintained at $37{ }^{\circ} \mathrm{C}$ under $5 \% \mathrm{CO}_{2}$. A rotary shaker was used for circular movement at 70 rpm. BM: basal medium, SYs: synovium-derived cells, ACs: articular chondrocytes.

\section{Proliferation potential}

To compare the proliferative potency of the ACs and SYs, we defined and calculated the passaging growth rate (PGR). The PGR for each culture dish was calculated per culture day using the following formula: PGR $=$ (recovered cell numbers for a given passage/seeded number of cells for the passage)/culturing days until the next passage.

\section{Fluorescent dye staining}

To evaluate the morphology and the distribution within the spheroids with mixed ACs and SYs, isolated ACs and SYs were labelled with PKH-26 (Red Fluorescent Cell Linker Kit for General Cell Membrane Labelling; Sigma-Aldrich, St. Louis, MO, USA) and PKH-67 (Green Fluorescent Cell Linker Kit for General Cell Membrane Labelling; Sigma-Aldrich), respectively, prior to spheroid culture. The PKH fluorescent cell linker kits, which are stably incorporated and retained in the plasma membrane, are nonradioactive and lipophilic substances with no known cellular toxicity, having a fluorescent half-life of $>100$ days in erythrocytes (according to the manufacturer's package insert) (Samlowski et al., 1991). Labelling was performed according to the manufacturer's instructions, i.e., reacting $2.0 \times 10^{7}$ cells with $\mathrm{PKH}-26$ or $\mathrm{PKH}-67$ in F12/DMEM without serum at $25^{\circ} \mathrm{C}$ for $\min$.

\section{Manufacture of the scaffold-free spheroids}

We fabricated the mixed cellular scaffold-free constructs using HDSS modified from the original method (Fig. 1A) (Lee, 2007). Briefly, ACs and SYs were harvested and counted on a Burker-Turk haematocytometer with trypan blue staining, and subsequently resuspended in BM with $10 \%$ FBS. Recovered ACs and SYs were mixed at various ratios: 75:25, 50:50 and 25:75. ACs alone (100) and SYs alone (100) were also prepared for analysis (Fig. 1B). Upon mixing, $1.0 \times 10^{7}$ cells $/ 5 \mathrm{~mL}$ medium were plated in a low cell-binding culture dish $\left(60 \mathrm{~mm}\right.$ Hydrocell $^{\mathrm{TM}}$; Cellseed Co., Tokyo, Japan) and maintained in the shaking culture at $37{ }^{\circ} \mathrm{C}$ under $5 \% \mathrm{CO}_{2}$. A rotary shaker (Double Shaker NR-3; Taitec, Koshigaya, Japan) was used to maintain 
Table 1. Grading Scale for Gross Appearance. This table was extracted from Cook et al. (2003).

\begin{tabular}{lc} 
Description & Points \\
\hline Intraarticular adhesions & 2 \\
None & 1 \\
Minimal/fine loose fibrous tissue & 0 \\
Major/dense fibrous tissue & \\
Restoration of articular surface & 2 \\
Complete restoration & 1 \\
Partial restoration & 0 \\
No restoration & \\
Erosion of cartilage & 2 \\
None & 1 \\
Defect site/site border & 0 \\
Defect site and adjacent normal cartilage & \\
Appearance of cartilage & 2 \\
Translucent & 1 \\
Opaque & 0 \\
Discolored or irregular & $\mathbf{8}$ \\
\hline Maximum total &
\end{tabular}

Table 2. Histological Grading Scale for Defect Cartilage. This table was extracted from Wakitani et al. (1994).

\begin{tabular}{|c|c|}
\hline Category & Points \\
\hline \multicolumn{2}{|l|}{ Cell Morphology } \\
\hline Hyaline cartilage & 0 \\
\hline Mostly hyaline cartilage & 1 \\
\hline Mostly fibrocartilage & 2 \\
\hline Mostly noncartilage & 3 \\
\hline Noncartilage only & 4 \\
\hline \multicolumn{2}{|l|}{ Matrix Staining (Metachromasia) } \\
\hline Normal (compared with host adjacent & 0 \\
\hline cartilage) & 1 \\
\hline Slightly reduced & 2 \\
\hline $\begin{array}{l}\text { Markedly reduced } \\
\text { No metachromatic stain }\end{array}$ & 3 \\
\hline \multicolumn{2}{|l|}{ Surface Regularity } \\
\hline Smooth $(3 / 4)$ & 0 \\
\hline Moderate $(1 / 2-3 / 4)$ & 1 \\
\hline Irregular $(1 / 4-1 / 2)$ & 2 \\
\hline Severely irregular (1/4) & 3 \\
\hline \multicolumn{2}{|l|}{ Thickness of Cartilage } \\
\hline $2 / 3$ & 0 \\
\hline $1 / 3-2 / 3$ & 1 \\
\hline $1 / 3$ & 2 \\
\hline \multicolumn{2}{|l|}{ Integration of Donor with Host Adjacent Cartilage } \\
\hline Both edges integrated & 0 \\
\hline One edge integrated & 1 \\
\hline Neither edge integrated & 2 \\
\hline
\end{tabular}

circular movement at a speed of $70 \mathrm{rpm}$ (Fig. 1C). After 2-3 days of culture, the spheroidal cell aggregates were collected and divided for in vivo implantation and in vitro analysis including histology, immunohistochemistry, and gene expression.

\section{In vivo transplantation}

Cartilage and synovium tissues were harvested from two different donor rabbits (4 week old male Japanese white rabbits weighing approximately $1 \mathrm{~kg}$ ) according to time ( 8 or 16 weeks) after the transplantation of spheroids. These tissues were treated to obtain each of the primary cell lines. Twelve Japanese white rabbits (females, 16-18 weeks old, weighing $\sim 3 \mathrm{~kg}$ ) were used for transplantation in this study. The rabbits were anaesthetised with isoflurane (induction $4 \%$, maintenance $2.0 \%$ under $30 \%$ oxygen and $70 \%$ nitrous oxide). After a medial parapatellar incision to both legs, each patella was dislocated laterally, and a 
superficial osteochondral defect $(5 \mathrm{~mm}$ in diameter and 3 $\mathrm{mm}$ deep) was created on the patellar groove of the femur in both legs using a drill and a biopsy punch (Kai Industries, Seki City, Japan). The bottom of the subchondral bone was shaved to a plane using a biopsy punch until bleeding was seen from the marrow, as described previously (Nagai et al., 2008b). Rabbits were classified into two recipient groups: an injectable spheroid-implanted group, in which the scaffold-free transplants were allografted into the defect that was created, and a non-transplanted control group. Before allograft transplantation, spheroids were collected from a culture dish through micropipette tips and were then delivered into the defect using micropipette aspiration. The defect was filled with scaffold-free spheroids, which were processed and prepared with $1.0 \times 10^{7}$ cells in $200 \mu \mathrm{L}$ of medium, and was held stationary for 15 min without any additional fixation. The joint capsule and soft tissue were then closed in routine fashion. After recovery from the surgery, all animals were allowed to walk freely in their cages without splints.

\section{Morphologic evaluation in vitro and in vivo}

At the end of the study periods, the rabbits were euthanised with a lethal dose of $120 \mathrm{mg} / \mathrm{kg}$ sodium pentobarbital (Abbott Laboratories, Abbott Park, IL, USA).

Macroscopic evaluations of the transplanted areas were conducted at 8 or 16 weeks postoperatively. The six femoral knee joints per group $(n=3)$ were evaluated immediately after the rabbits were euthanised. The distal parts of the femur were harvested and observed. The cartilage defects were examined and scored macroscopically for the presence of intraarticular adhesions, completeness of surface restoration, signs of cartilage erosion, and the overall appearance of each defect, including smoothness, colour, and integrity, according to a gross appearance grading scale consisting of four categories with a total score ranging from $0-8$ points (best score, 8 ; worst score, 0), as described by Cook et al. (2003) (Table 1).

After macroscopic evaluation, the distal part of the femur was excised and fixed in $4 \%$ paraformaldehyde for 7 days. Each specimen was decalcified in a solution of 10 $\%$ EDTA in distilled water ( $\mathrm{pH} 7.4$ ) for 2-3 weeks and then embedded in paraffin wax and sectioned perpendicularly (4 $\mu \mathrm{m}$ sections) through the centre of the defect. The sections were then deparaffinised according to standard procedures.

Spheroid samples were washed with PBS, then immersed in PBS containing $15 \%$ and $20 \%$ sucrose and immediately frozen, embedded in OCT compound (Sakura Finetechnical, Tokyo, Japan), and sectioned at a thickness of $4 \mu \mathrm{m}$.

After pretreatment of tissue and spheroid specimens, each section was stained with toluidine blue (for detection of proteoglycans) and safranin $\mathrm{O}$ (for detection of glycosaminoglycans) for histological evaluation. Immunohistochemistry was conducted as described previously (Nagai et al., 2008b). In brief, the sections were treated with $0.005 \%$ proteinase (Type XXIV; Sigma-Aldrich) for $30 \mathrm{~min}$ at $37^{\circ} \mathrm{C}$ for antigen retrieval. For types I and II collagen, a primary mouse monoclonal antibody (Daiichi Fine Chemical Co., Toyama, Japan) diluted 1:200 in PBS $+1 \%$ bovine serum albumin (BSA;
Sigma-Aldrich) (final concentration $2.5 \mathrm{mg} / \mathrm{mL}$ ) was placed on the section overnight at $48^{\circ} \mathrm{C}$. The remaining sections were incubated with PBS instead of specific primary antibodies and stained as negative controls. The slides were washed with PBS after incubation for $1 \mathrm{~h}$ at room temperature with biotin-conjugated goat anti-mouse secondary antibody (Cortex Biochem, San Leandro, CA, USA) for type I collagen and type II collagen. The slides were then treated with horseradish peroxidase-labelled streptavidin (Dako, Glostrup, Denmark) for $1 \mathrm{~h}$ and were then soaked in a $0.05 \%$ solution of diaminobenzidine in Tris-HCl buffer ( $\mathrm{pH} 7.6$ ) containing $0.005 \%$ hydrogen peroxide. The slides were counterstained with Mayer's haematoxylin and evaluated microscopically.

The sections were scored according to a histological grading scale. We used Wakitani's Scale consisting of 5 categories (cell morphology, matrix staining, surface regularity, cartilage thickness, and integration of donor with host) with a total score ranging from 0 to 14 points (best score, 0 ; worst score, 14) as described by Wakitani et al. (1994) (Table 2). The total scores were compared between groups.

Morphologic evaluation of the spheroids was performed using phase-contrast microscopy and fluorescence microscopy (AX70; Olympus, Tokyo, Japan). To evaluate the location and distribution of cells in the spheroid structures composed of ACs and SYs, the spheroids were analysed using the lambda stack function of the confocal microscope (LSM 510 Meta; Zeiss, Oberkochen, Germany).

The threshold for PKH67 and PKH26 was set by evaluating the highest exposure at which the unlabeled ACs or SYs showed no autofluorescence.

\section{RNA extraction and reverse transcription- polymerase chain reaction}

Intact total RNA was isolated and extracted from spheroids with various cellular ratios (SY:AC: 100:0, 75:25, 50:50, 25:75, 0:100 ) both at the beginning $(0 \mathrm{~h})$ and on day 3 of HDSS using the SV Total RNA Isolation System (Promega, Madison, WI, USA), which included DNase digestion and spin column purification. 18S ribosomal RNA was used as an internal standard (Applied Biosystems, Foster City, CA, USA). The primers for rabbit collagen type I and II were obtained from Invitrogen and designed using Primer Express 3.0 (Applied Biosystems), based on sequences from the GenBank database ([Genbank: D49399 and D83228] respectively). For rabbit collagen type I the primers used were GCCTCGCTCACCACCTTCT (forward) and CAATCTGGTTGTTCAGAGACTTCAG (reverse). For rabbit collagen type II the primers used were GCAGCACGTGTGGTTTGG (forward) and CAGGCTGCTGTC TCCATAGCT (reverse). For each sample, $2 \mu \mathrm{g}$ of total RNA was reverse transcribed into cDNA using Multi- Scribe Reverse Transcriptase (Applied Biosystems) and Random Hexamers (Applied Biosystems). For PCR $5 \mu \mathrm{L}$ of cDNA template was amplified in a 25 $\mu \mathrm{L}$ reaction volume of GeneAmp PCR buffer (Applied Biosystems), containing $5.5 \mathrm{mM} \mathrm{MgCl}, 200 \mu \mathrm{M}$ of each $\mathrm{dNTP}, 0.5 \mu \mathrm{M}$ of appropriate primer pairs and 1 unit of AmpliTaq Gold DNA polymerase (Applied Biosystems). 


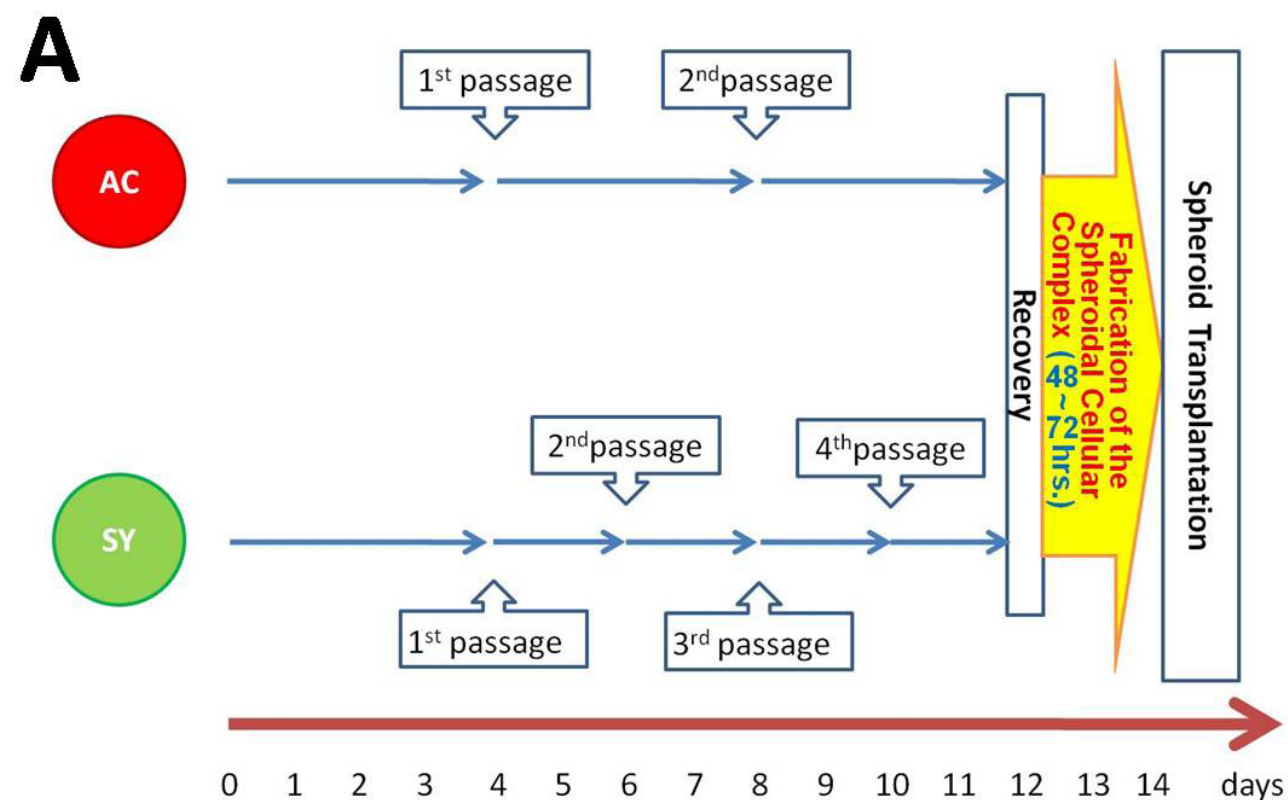

Culture periods(day) : 14 days
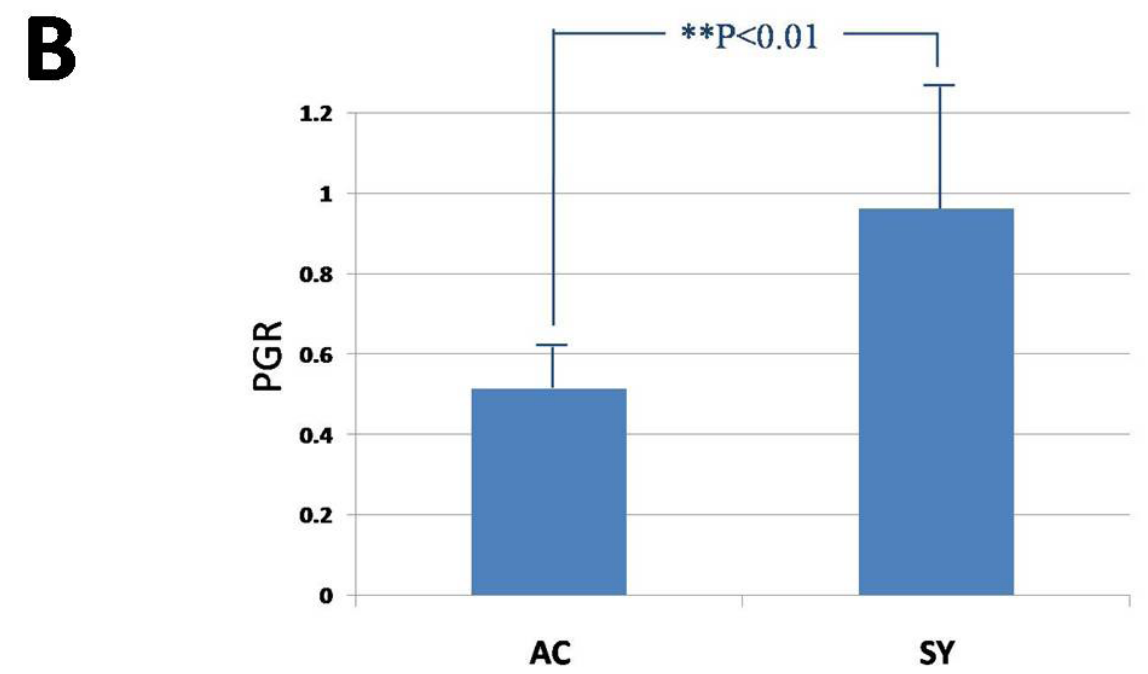

Fig. 2. HDSS schedule and passaging growth rate. (A) Schedule for manufacturing the SY-AC spheroids. During 11-12 days of continuous culture passaging, we performed three passages for ACs and five passages for SYs. The third AC passage and the fifth SY passage were utilised to fabricate the scaffold-free spheroids. After 2-3 days of HDSS, the cellular aggregates were considered stable enough to be handled. (B) Comparison of proliferative potency between the SYs and ACs. The PGR for the SYs was significantly higher than that of the ACs. PGR: passaging growth rate.

The reaction mixture was kept at $95{ }^{\circ} \mathrm{C}$ for $10 \mathrm{~min}$ for a 'hot-start', followed by PCR of 40 cycles. Each cycle included denaturation at $95{ }^{\circ} \mathrm{C}$ for $15 \mathrm{~s}$, followed by annealing and extension at $61{ }^{\circ} \mathrm{C}$ for $1 \mathrm{~min}$. A total of 10 $\mu \mathrm{L}$ of each PCR product was applied to $3 \%$ NuSieve ${ }^{\circledR}$ 3:1 agarose gel (Lonza Rockland, Rockland, ME, USA) for electrophoresis. Resolved bands on the gels were visualised with $0.5 \mathrm{mg} / \mathrm{L}$ ethidium bromide on a densitograph system (ATTO Biotechnologies, Tokyo, Japan).

\section{Statistical analysis}

Data are presented as means \pm standard deviations (SD) of measurements from 6 independent experiments. Groups were compared by analysis of variance (ANOVA). Student's $t$-test was used to determine significant differences. Values of $p<0.05$ were considered the minimum level of statistical significance.

\section{Results}

Primary cultures of chondrocytes and synoviumderived cells from articular cartilage

Using the methods described above, the recovered numbers of AC and SY cells from a single knee joint were $850.9 \times 10^{4}$ $\pm 24.2 \times 10^{4}$ and $593.3 \times 10^{4} \pm 47.0 \times 10^{4}$, respectively. During 

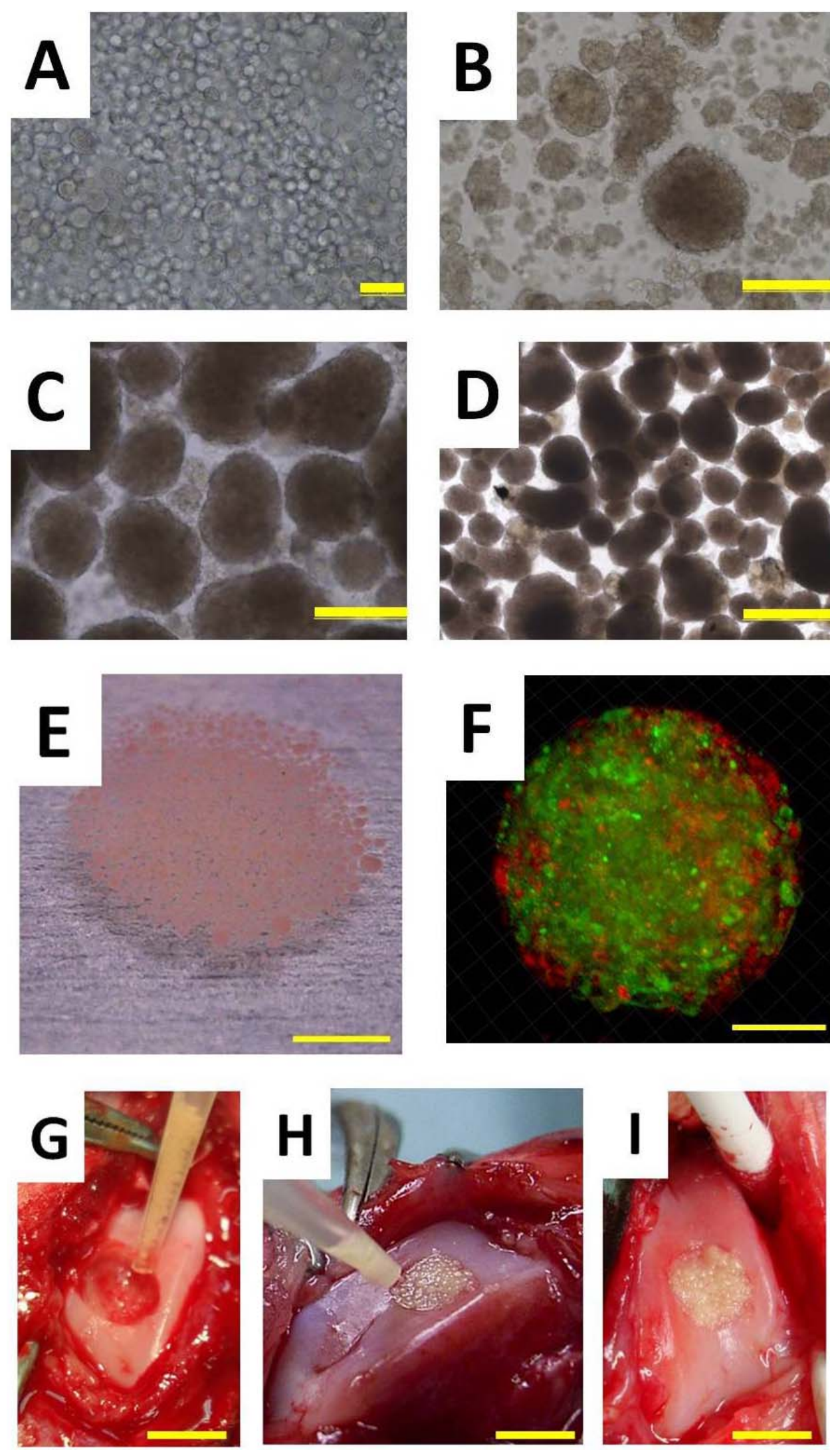

Fig. 3. Implantation of injectable spheroids. Changes in the appearance of representative cellular aggregates $(75: 25$ SY:AC) with HDSS over time compared to other SY:AC ratios under a phase contrast micrograph at (A) $0 \mathrm{~h}$, bar $=$ $50 \mu \mathrm{m}$; (B) $12 \mathrm{~h}$, bar = $200 \mu \mathrm{m}$; (C) $24 \mathrm{~h}$, bar $=200 \mu \mathrm{m}$; and (D) $36 \mathrm{~h}$, bar $=500 \mu \mathrm{m}$. (E) Macroscopic appearance of the spheroids (75:25 SY:AC) after HDSS. Bar $=5 \mathrm{~mm}$. (F) A representative spheroid (50:50 SY:AC) under confocal microscopy. Bar $=100 \mu \mathrm{m}$. (G) The spheroids were collected and delivered to the osteochondral defect site using micropipette aspiration through a micropipette tip. (H) The defect was filled with scaffold-free spheroids (75-25 $\mathrm{SY}: \mathrm{AC}$ ) in $200 \mu \mathrm{L}$ medium and (I) left stationary for $15 \mathrm{~min}$ without any additional fixation. Bar $=5 \mathrm{~mm}$. 
A

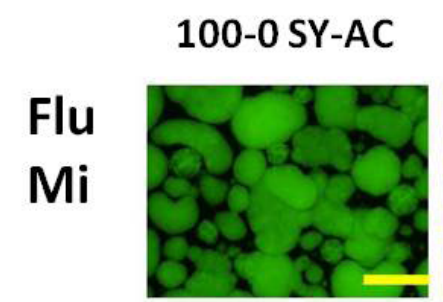

75-25 SY-AC

50-50 SY-AC

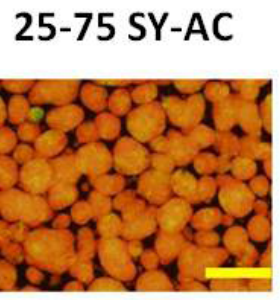

0-100 SY-AC

T.B
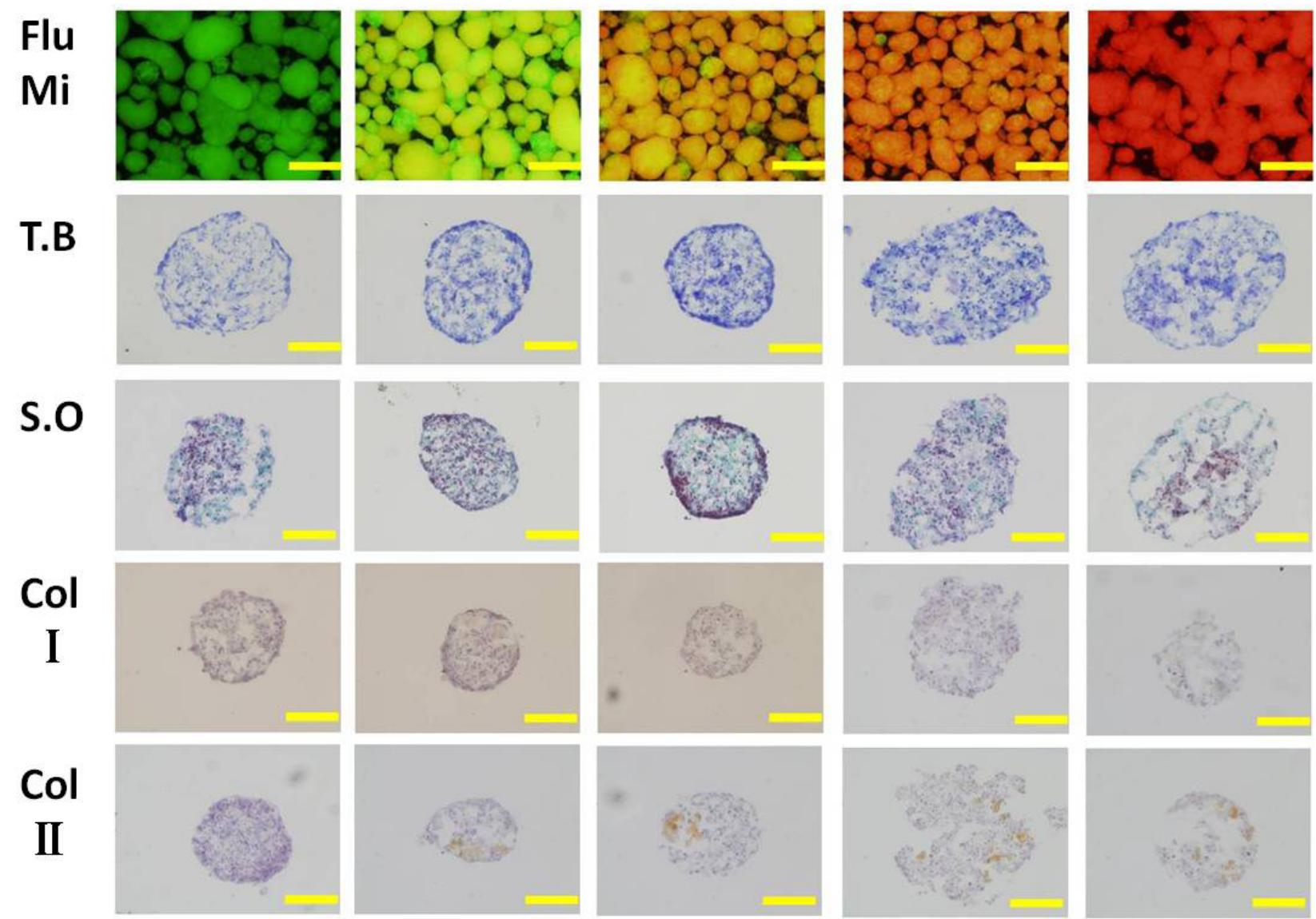

B

\section{$\begin{array}{lllll}1 & 2 & 3 & 4 & 5\end{array}$}

COL I

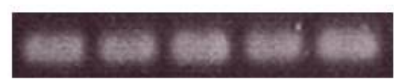

COL II

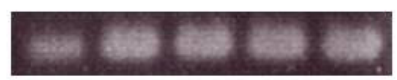

$18 \mathrm{~S}$ rRNA

\section{$\begin{array}{lllll}1 & 2 & 3 & 4 & 5\end{array}$}
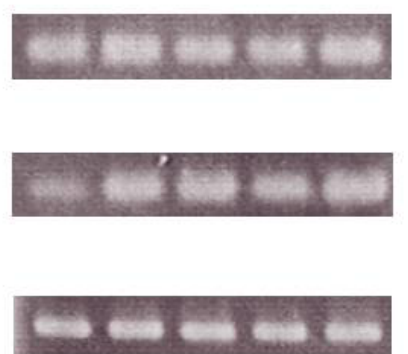

\section{day 3}

Fig. 4. Morphological analysis and RT-PCR results of spheroids. (A) Morphologic appearance under fluorescence microscopy $(\mathrm{Flu} \mathrm{Mi}, \mathrm{Bar}=500 \mu \mathrm{m})$ of the completed structure of each spheroid type after a $36 \mathrm{~h}$ culture. For histological analysis, spheroids with different ratios of SY:AC subjected to 3 days of HDSS were evaluated with toluidine blue (TB) and safranin $\mathrm{O}(\mathrm{SO})$ staining. There were no prominent differences in the staining patterns among the cell composition ratios for any structures. None of the spheroids showed a normal cartilage phenotype regardless of cellular composition. For all spheroid compositions, the ECM was sparsely and irregularly stained with SO and TB, suggesting a small amount of glycosaminoglycans and proteoglycans, and was also positive for type I and type II collagen. Bar $=100 \mu \mathrm{m}$. (B) RT-PCR analysis showed that both type I and type II collagen was expressed in each spheroid, regardless of cellular composition. 


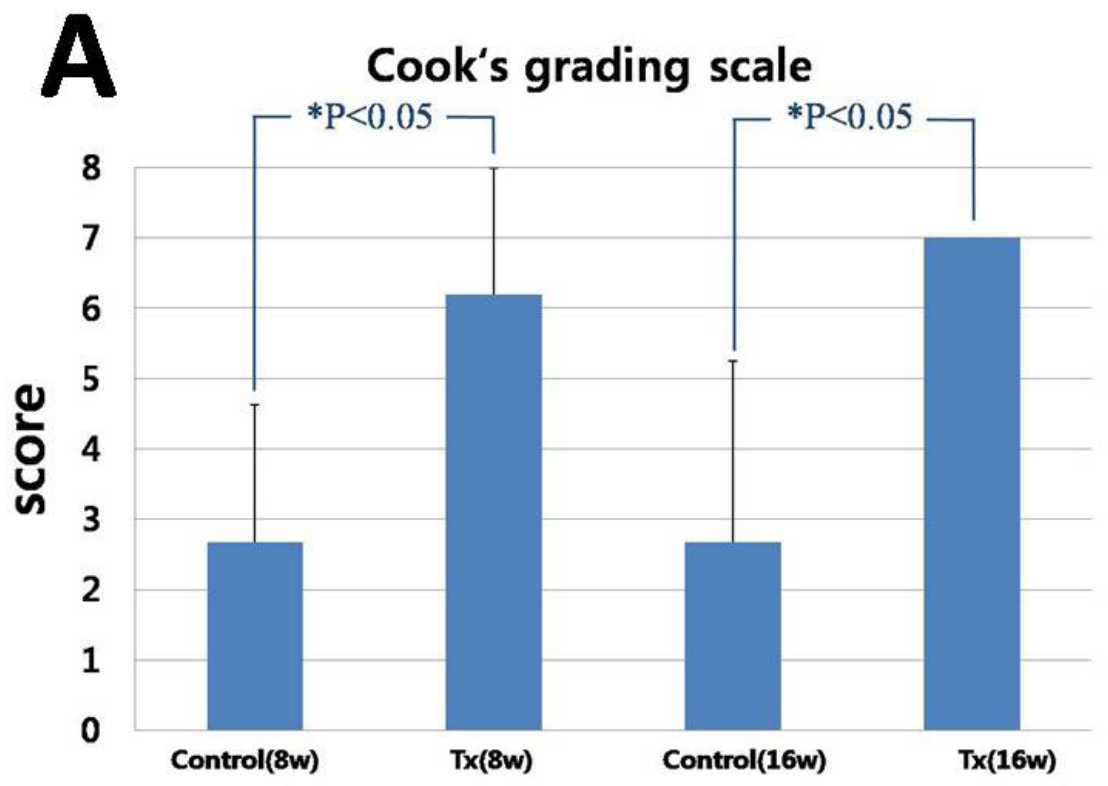

B

Wakitani's histological score

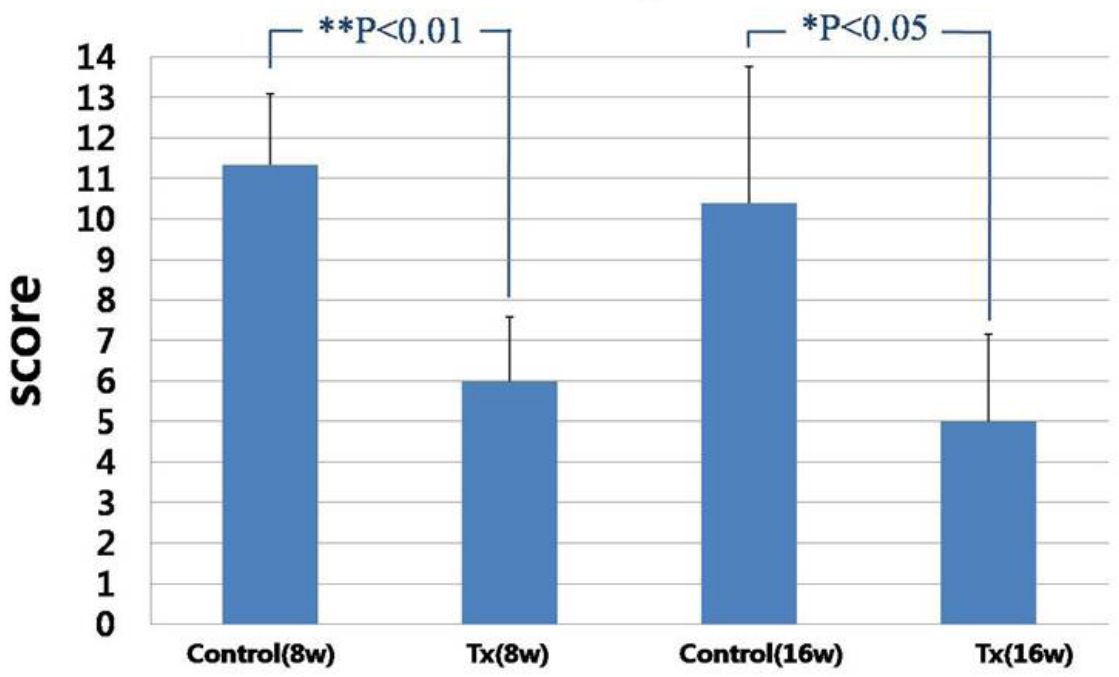

Fig. 5. Grading scores for gross and microscopic appearance. (A) Cook's scores. (B) Wakitani's histological scores.

11-12 days of continuous culture passaging, it was possible to trypsinise three times for ACs and five times for SYs. Ultimately, the third passage of ACs and the fifth passage of SYs were utilised to fabricate the scaffold-free spheroids (Fig. 2A). It has previously been reported that SYs have the characteristics of MSCs when isolated and cultured according to the method of primary culture described by (Koga et al., 2007; Koga et al., 2008a).

\section{Proliferative capacity of ACs and SYs}

The proliferative potency of the SYs was significantly greater than that of the ACs. The PGRs for the ACs and SYs were $0.51 \pm 0.11$ and $0.96 \pm 0.29$, respectively (Fig. 2B). The PGR for the SYs was approximately double that for the ACs.

\section{Morphological analysis of spheroids}

Analyses were performed with ACs and SYs derived from the third or fifth passage, respectively. Fig. 3A-D shows the changes in the appearance of representative cellular aggregates (75:25 SY:AC) with time among other $\mathrm{SY}$ :AC ratios under a phase contrast micrograph. The cells undergoing HDSS gathered into small numbers of cell clusters and anchored onto others over time. The surfaces of the cell aggregations gradually became smooth from an original rough state. The final diameters of the spheroids were $\sim 250-700 \mu \mathrm{m}$, divided into two groups according to size. The smaller spheroids were $\sim 250 \pm 100 \mu \mathrm{m}$ and the larger spheroids were $\sim 700 \pm 250 \mu \mathrm{m}$. The spheroidal cell aggregates were macroscopically observed within $12 \mathrm{~h}$ of HDSS (Fig. 3B-E). After 2-3 days of HDSS, the cellular aggregates were considered stable enough to be handled with micropipette aspiration (Fig. 3E, G-I). 


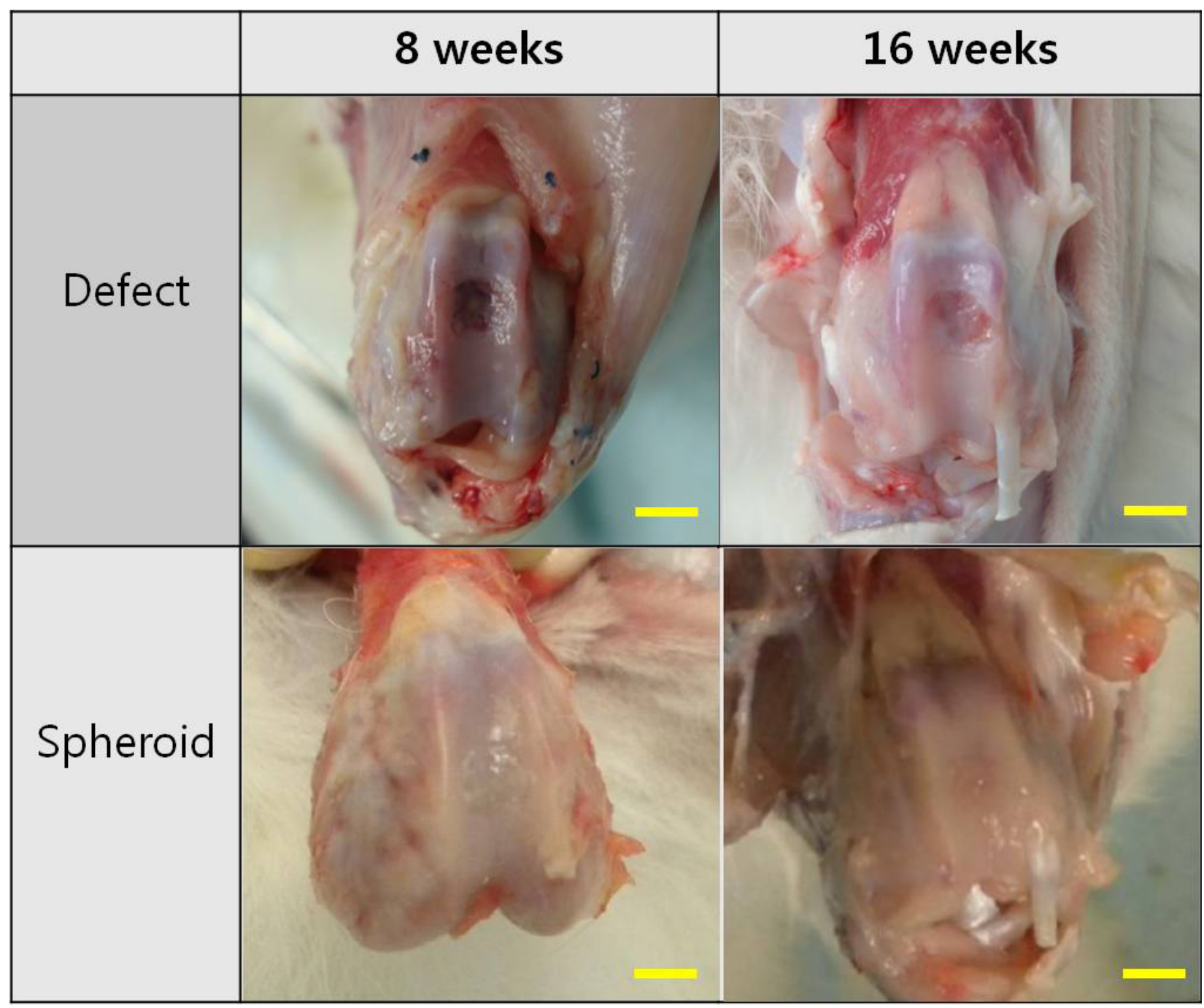

Fig. 6. Macroscopic analyses for the in vivo study. Gross observations of femoral condyles at 8 and 16 weeks after surgery. Bar $=5 \mathrm{~mm}$.

Morphological findings visualised either by confocal microscopy (Fig. 3F) or by fluorescence microscopy show that the SYs and ACs were randomly distributed without any particular pattern, independent of the cell component ratio, in all structures. The morphologic appearance of a completed spheroid structure after $36 \mathrm{~h}$ culture is shown under fluorescence microscopy in Fig. 4A.

For histological analysis, spheroids with various mixing ratios subjected to 3 days HDSS were evaluated with toluidine blue and safranin $\mathrm{O}$ staining. The cross sections of the spheroid samples elucidate the internal location and distribution of the cells and ECM such as proteoglycans and glycosaminoglycans. In addition, the results of immunohistochemistry for collagen ECM in the spheroids provide an indication of the degree of similarity with normal cartilaginous tissue. In the histological results, there were no prominent differences in the staining patterns among any of the specimens with differing cell component ratios. A normal phenotype for cartilage was indicated by both safranin O-positive glycosaminoglycan-rich areas and metachromatic sites, evoked by toluidine blue.
However, the histological results found no spheroids with a normal cartilage phenotype, regardless of the cellular component ratio. In the cross-sectional area of all of the spheroids, ECM was sparsely and irregularly stained with safranin $\mathrm{O}$ and toluidine blue, suggesting a small amount of glycosaminoglycans and proteoglycans (Fig. 4A) and, furthermore, was positive for type I and type II collagen (Fig. 4A). Interestingly, this phenomenon also occurred for spheroids made up solely of ACs or SYs (0:100 SY:AC and 100:0 SY:AC).

\section{Gene expression}

To investigate the expression of type I and type II collagen, similar samples of spheroids with the five different mixing ratios were prepared to elucidate the effect of time during HDSS. Real time PCR analysis (RT-PCR) showed that both type I and type II collagen was expressed in each spheroid, regardless of cellular component ratio (Fig. 4B). The time courses (initiation vs. day 3 ) for mRNA expression of type I and type II collagen in the HDSS constructs showed an irregular pattern. 
A

\begin{tabular}{|c|c|c|c|c|}
\hline & Toluidine Blue & Safranin 0 & Collagen type I & Collagen type II \\
\hline $\begin{array}{l}\text { Defect } \\
8 \text { weeks }\end{array}$ & & & & \\
\hline $\begin{array}{c}\text { Defect } \\
16 \text { weeks }\end{array}$ & & & & \\
\hline $\begin{array}{l}\text { Spheroid } \\
8 \text { weeks }\end{array}$ & & & & \\
\hline $\begin{array}{l}\text { Spheroid } \\
16 \text { weeks }\end{array}$ & & & & \\
\hline
\end{tabular}

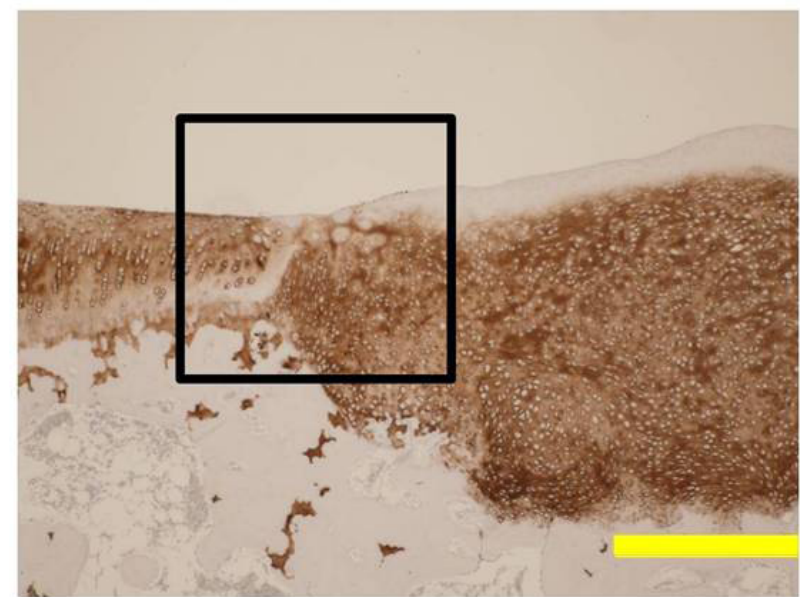

B

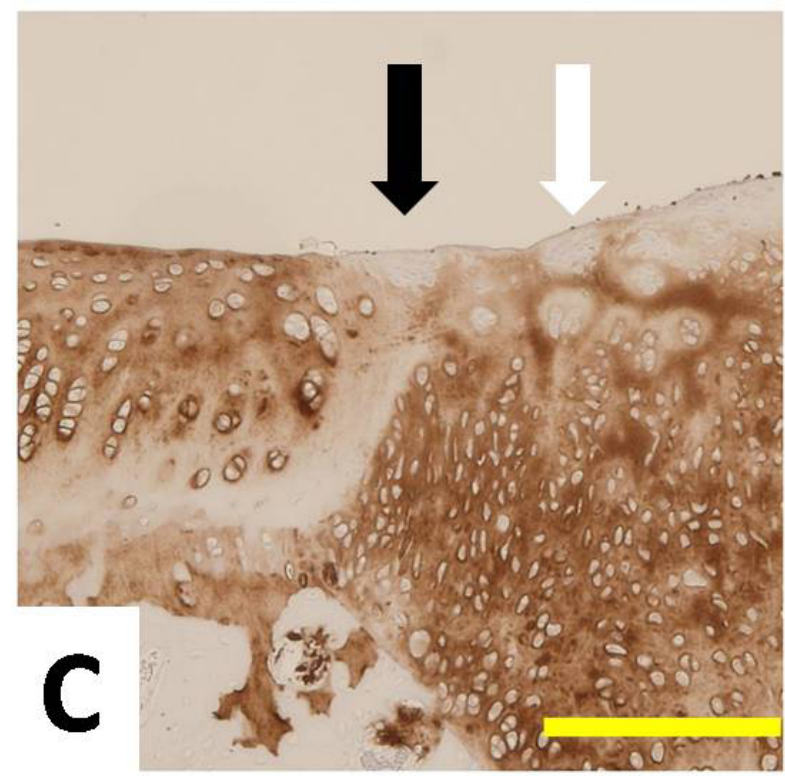

Fig. 7. Histological analyses. (A) Results for the in vivo study of toluidine blue and safranin O staining, and type I and type II collagen. Bar $=1 \mathrm{~mm}$. (B) Histological observations of the implanted site 8 weeks after allotransplantation. Bar $=500 \mu \mathrm{m}$. (C) Magnified image of the black box. The black arrowhead indicates the interface between normal cartilage tissue and the regenerated tissue, and the white arrowhead indicates a chondrocyte clustering area. Bar $=$ $200 \mu \mathrm{m}$.

\section{Examination of the transplanted spheroids}

As the optimal ratio of $\mathrm{ACs}$ and $\mathrm{SY}$ s for in vivo implantation, we selected 75:25 SY:AC spheroids for in vivo implantation study. We transplanted the 2- to 3-day spheroids to the total-thickness-defect model. It required $55.1 \pm 6.4 \mathrm{~h}$ to prepare the spheroidal transplants firm enough to be handled with micropipette aspiration, using HDSS for the implantation experiments. The operations were uneventful and all of the rabbits immediately resumed normal cage activity. No signs of arthritis, such as cartilage erosion or severe synovial proliferation, were observed in any of the knees that were operated on.
Based on macroscopic observations, the spheroidimplanted group had better integration of host cartilage, and the defects repaired by the spheroids were smoother than in the non-transplanted control group (Fig. 6). The defects in the spheroid-implanted group were filled with smooth white tissue compared with the non-transplanted control group. The borders of the reparative tissue were also visible and the colour of the tissue was slightly different from that of the surrounding normal cartilage. However, the defects in the non-transplanted control group remained empty or covered in reddish tissue. The global macroscopic scores for the spheroid-implanted group ( 6 knee joints) were 
statistically better than ( 8 weeks; $p=0.0130,16$ weeks; $p$ $=0.0110)$ those for the non-transplanted control group (6 knee joints) (Fig. 5A).

In the spheroid-implanted group, the defects were filled with reparative tissue in contrast to those of the non-transplanted control group. In addition, the repair site appeared to be filled with cartilaginous tissues, which were strongly stained with safranin $\mathrm{O}$ and toluidine blue, positive for type II collagen, and negative for type I collagen (Fig. 7A). The reparative tissue had a smooth surface and was connected with adjacent normal cartilage at 8 and 16 weeks after the operation. No infiltration of inflammatory cells within the subchondral bone was seen. In contrast, the surface of the non-transplanted control group (Fig. 7A) was irregular and the thickness of the tissue was less than that of the spheroid-implanted group. In the non-transplanted group, the defects were filled mainly with fibrous tissue concealing the lower portion of the repair tissue. The intensity of safranin $\mathrm{O}$ and toluidine blue and anti-type II collagen, as well as the areas of staining, were lower in the non-transplanted control group. Basal and lateral integration of the grafts were good (Fig. 7B, C). Black arrowheads (Fig. 7C) indicate the interface between normal cartilage tissue and the regenerated cartilaginous tissue at the site of the implanted spheroids. Complete filling of the defect and integration at the rim was observed with highly positive immunohistochemistry for collagen type II. A cluster formation of several chondrocytes around the interface of the regeneration area was observed (Fig. 7C). Furthermore, Wakitani's scores (Fig. 5B) for the spheroidimplanted group ( 6 knee joints) were significantly better than ( 8 weeks; $p=0.0005,16$ weeks; $p=0.0278$ ) those of the control group ( 6 knee joints) at 8 and 16 weeks. The untreated defects had poorer scores at 8 weeks than at 16 weeks.

\section{Discussion}

Since synovium-derived mesenchymal stem cells (SYMSCs) were first identified and successfully isolated in 2001 (De Bari et al., 2001) as a new origin among MSC families, they have been increasingly regarded as a versatile therapeutic cell species for musculoskeletal regeneration, particularly for reconstruction of cartilage, bone, adipose tissue, tendons, muscles, etc. In addition to having general multipotency in common with the MSC community, SYMSCs excel compared to other-sourced MSCs in their higher proliferation and superiority in chondrogenesis (Sakaguchi et al., 2005; Fan et al., 2009). Furthermore, their multipotent capacity is not influenced by donor age, cell passages, or cryopreservation (De Bari et al., 2001).

In this study, we chose SYs as a partial replacement for ACs as a mixture component, and were able to fabricate mixed SY-AC constructs as spheroid aggregates. SYs appear to be a promising cell source for cartilage regeneration, since synovium-derived cells have also been chosen as a substantial source for chondrogenesis (Shimomura et al., 2010). Compared to other sources of MSCs, SY-MSCs show higher proliferative and chondrogenic ability, and large amounts of SY-MSCs can be easily obtained from small amounts of synovial tissue. In clinical applications, cell numbers obtained from biopsies are quite limited, and there are disadvantages in performing cell proliferation with AC alone. The HDSS system rapidly generates scaffold-free artificial tissue with relatively few cells compared with other systems. In addition, the synovial tissue has a high self-regenerative ability. When SYs are used as a partial cell component for clinical ACI, it is expected that a method can be developed that will minimise sacrifice of undamaged cartilage within the same joint.

SYs display higher proliferative capacity than ACs (Fig. 2B), which is consistent with the results of previous studies (De Bari et al., 2001; Sakaguchi et al., 2005; Fan et al., 2009). Technically, we note that we used SYs for HDSS rather than SY-MSCs, as we did not prove that our SYs were SY-MSCs and differentiation assays, such as for chondrogenesis, were not performed.

The delivery of the spheroids using micropipette aspiration was straightforward, because their size range was small enough to place injectable units through the syringe or micropipette tips.

The results of in vitro morphological analysis, including confocal microscopy, fluorescence microscopy, and histological findings, indicated that the SYs and ACs were irregularly and randomly located within the spheroids. The phenotypes of the interior of the spheroids were far from the normal cartilage phenotype regardless of the cellular component ratio. The ECM was defective and sparsely stained with safranin $\mathrm{O}$ and toluidine blue in addition to insufficient intensity of positive staining for type I and type II collagen in immunohistochemistry, suggesting small amounts of glycosaminoglycans, proteoglycans, and collagen fibres. The same pattern of results was observed for spheroids composed of AC alone (100:0) and SY alone (0:100).

The results of the gene expression analysis showed strong expression of collagen ECM (type I and type II) for all conditions (Fig. 4B). As this was assessed using RT-PCR, we were not able to determine the exact relative levels of expression of the ECM gene for all conditions. Additional analyses, such as RT-PCR, are needed to quantify exactly the relative expression level of ECM among the different cellular ratios. We suppose that there are several explanations for the different results of ECM expression obtained using histological analysis and RTPCR. Although we can speculate that the real accumulation of ECM secreted by the cells in each spheroid does not always correspond to the results of the RT-PCR analysis, these are mere ECM mRNA expression levels, which do not always coincide with the real secretion of the ECM protein after translation. Therefore, the difference between the immunohistochemistry and RT-PCR results regarding ECM levels may represent differences between the levels of transcription and translation of ECM. We are not certain of the reason for this discordance at present. Shear stress resulting from HDSS may be related to this phenomenon. However, we need to perform additional analyses to verify the reasons for this discrepancy substantially. Conversely, as histological analysis only provides fragmentary information of spheroids, 2D cross sections of spheroids 
have, thus far, been limited for 3D spheroids that exhibit random distribution of ACs and SYs. In addition, the results of the RT-PCR analysis reflect the complete information of 3D spheroids.

Chondrocyte 3D culture techniques such as pellet culture, bioreactor culture have been developed to obtain a large amount of cultured cells with a well-maintained cartilage phenotype. Manipulation of the culturing environment for chondrocytes presents the most feasible mechanism for optimising cell behaviour and phenotype (Lin et al., 2006). Using an ordinary pellet culture, after 2 weeks, the ECM in the pellets was comparable with that of normal cartilage. Chondrocyte redifferentiation from monolayer-cultured chondrocytes has been demonstrated to occur in neocartilage over 14 days (Zhang et al., 2004). However, our scaffold-free spheroids are still immature de novo cartilage grafts, which are expected to regenerate into normal cartilaginous tissue in situ and in vivo within full-thickness osteochondral defects as soon as they are prepared through HDSS. The HDSS period (2-3 days) in the present study was shorter than usual in vitro culture length for chondrogenesis (14-21 days). It is suggested that neo-cartilage in 3D culture is observed after 14-21 days of continuous culture. Together with the previous literature, this reflected the fact that the duration of our $3 \mathrm{D}$ culture was too short to allow re-differentiation from the monolayer culture of ACs and SYs passaged continuously (Nagase et al., 2008; Zhang et al., 2004). Furthermore, our system can yield mass production of transplantable chondrogenic tissue. However, most of the pellet culture systems are not designed to produce transplantable tissue; rather, they are an analytical tool that usually leads to the formation of a single aggregate per experiment.

The co-culture of ACs and MSCs has gained considerable attention recently. Monolayer co-culture of immortalised human ACs with immortalised human MSCs in the absence of exogenous TGF- $\beta$ resulted in chondrocytic differentiation of the MSCs, based on collagen type II protein expression (Chen et al., 2009), and the MSCs were committed to chondrocytes, which are influenced by the cellular microenvironment and the paracrine signals of chondrocytes (Grassel and Ahmed, 2007). The HDSS system provides this radical microenvironment to MSCs from ACs. However, we suggest that our HDSS culture system shortens the preparation time for fabricating a considerable quantity of spheroids, and can substantially shorten the total time required for an ex vivo procedure. Moreover, a high-density culture of chondrocytes, which promotes cell to-cell contact, has been significantly associated with extracellular matrix biosynthesis (Watt, 1988). In the present study, ACs and SYs were cultured together in a high-density suspension state on a nonadhesive culture plate while maintaining continuous suspension conditions; the cells then adhered to each other to develop spheroidal cell mixtures, producing limited ECM due to the short culture time. The molecular mechanism for cell adhesion under rapid formation of spheroid may involve several molecules such as integrins ( $\alpha 10, \alpha 3$, and $\beta 1$ ) (Gigout et al., 2009; Mitani et al., 2009; Shimaya et al., 2010), fibronectin (Mitani et al., 2009), N-cadherins (Djouad et al., 2007; Quintana et al., 2009).
However, in general, a high-density culture may limit the amount of mass transfer. At present, our system, with a product size small enough for injection, is superior for delivering transplants. In the animal experiments, articular cartilage defects in which SY-AC spheroids were implanted in vivo showed improved histological findings (Figs. 5B and 7). The allografted spheroidal aggregates differentiated slowly to chondrocytes in the articular cartilage defects and produced an extracellular matrix similar to that of hyaline cartilage, thereby maintaining the chondrocyte phenotype. The implanted spheroids exhibited proliferation and differentiation activity in the articular cartilage defects, resulting in the formation of hyaline cartilage.

No signs were observed of immunologic rejection or degeneration of the reparative tissue during the observation period. As a potential limitation of the present study, we did not perform detailed laboratory investigations to detect specific immunologic reactions such as development of antibodies or cell-mediated responses.

We choose 75:25 SY:AC spheroids to transplant for cartilage regeneration. According to the previous literature (Ochi et al., 2002; Shimomura et al., 2010), spheroids composed of AC alone and SY alone may have the potential to produce hyaline cartilage for in vivo implantation, furthermore, other ratios of SY:AC may also have the potential to produce reparative tissue for regenerate cartilage; however, In the view point of utility of SYs as a partial replacement for ACs in ACI, we applied this ratio $(75: 25)$ in the present implantation study since this formation maximise the merit and efficacy of using SYs of high proliferation with less invasive procedure and donor site morbidity among other SY:AC ratios. Further in vivo studies is needed to determine the exact nature of implanted spheroids including transplantation with different other ratios of SY:AC and monitoring the transplants fate with fluorescent labelling.

Interestingly, numerous cluster formations of chondrocytes near the interface with the regenerative tissue were observed. This clustering phenomenon is a sign of repair in early osteoarthritis (Frenkel and Di Cesare, 1999). This result indicates that scaffold-free spheroids inserted into osteochondral defects show high regenerative capacity. Koga et al. (2008b) described the viscosity and adhesive properties of SYs in an ex vivo analysis in rabbits and demonstrated that the number of attached cells increased in a time-dependent manner; more than $60 \%$ of the cells attached within 10 min under normal gravity. Similarly, we held the defects stationary after implantation for more than $10 \mathrm{~min}$ (15 min) without additional fixation such as a periosteal patch. Accordingly, dislocation of spheroids and leakage from the implanted sites were minimal. The present results are consistent to some extent with the earlier report (Koga et al., 2008b). However, the mechanical strength properties of regenerated articular cartilage still remain to be investigated through in vivo studies on larger animals (i.e., sheep or pigs).

We confirmed that in the early stage of transplantation, effective restoration of articular cartilage is seen with reparative mixed cells derived from MSCs and ACs, which can induce recruited MSCs into ACs and trigger chondrogenesis (Kaneshiro et al., 2006; Nagai et al., 
2008b), and achieved good restoration results over the long term. We therefore hypothesised that good cartilage repair may be achieved by providing a proper quantity of an initiator (ACs) and a comparable quantity of materials (SY-MSCs or bone marrow-derived MSCs) to induced ACs in the osteochondral defect, no matter whether it is full-thickness or partial.

To the best of our knowledge, no previous studies have demonstrated the feasibility of cellular transplants consisting of different cells or origins of cells. The HDSS maintains ACs and SYs in a high-density suspension for a short period of time and yields 3D minimal building units of spheroids. Frequent cell-cell contact, as permitted by growth at high density, stimulates the formation of aggregates. This technology may have an advantage in a clinical setting, because it is scaffold-free and uses no artificial substances. With this new technique, broad lesions can be treated free of scaffolds and artificial biomaterials. Effective use of SYs and minimal invasiveness are anticipated advantages of this novel method for replacement of chondrocytes in ACI.

\section{Conclusions}

Using the HDSS method, we can successfully prepare a large quantity of cellular spheroids in a short period using mixed ACs and SYs, whose high proliferation potency and differentiation potency does not change. The allografted grafts exhibited differential activity to chondrocytes showing in vivo extracellular matrix production. These results suggest an ability to achieve regeneration of articular cartilage through implantable spheroids as a therapeutic minimal building unit.

\section{Acknowledgements}

The authors thank Dr. Ichiro Sekiya (Section of Cartilage Regeneration, Graduate School, Tokyo Medical and Dental University, Japan) for providing useful information, comments, and technical critique with respect to primary culturing of synovium-derived cells, whose MSC characteristics had previously been reported by his group (Koga et al., 2007; Koga et al., 2008a).

This research was supported by Grant-in-Aid for Challenging Exploratory Research from Ministry of Education, Culture, Sports, Science and Technology in Japan and Basic Science Research Program through the National Research Foundation of Korea (NRF) funded by the Ministry of Education, Science and Technology (20100024188).

\section{References}

Anderson JM, Rodriguez A, Chang DT (2008) Foreign body reaction to biomaterials. Semin Immunol 20: 86-100.

Badylak SF, Gilbert TW (2008) Immune response to biologic scaffold materials. Semin Immunol 20: 109-116.

Brehm W, Aklin B, Yamashita T, Rieser F, Trub T, Jakob RP, Mainil-Varlet P (2006) Repair of superficial osteochondral defects with an autologous scaffold-free cartilage construct in a caprine model: implantation method and short-term results. Osteoarthritis Cartilage 14: 12141226.

Brittberg M, Lindahl A, Nilsson A, Ohlsson C, Isaksson O, Peterson L (1994) Treatment of deep cartilage defects in the knee with autologous chondrocyte transplantation. N Engl J Med 331: 889-895.

Buckwalter JA, Mankin HJ (1998) Articular cartilage: Degeneration and osteoarthritis, repair, regeneration, and transplantation. Instr Course Lect 47: 487-504.

Chen WH, Lai MT, Wu AT, Wu CC, Gelovani JG, Lin CT, Hung SC, Chiu WT, Deng WP (2009) In vitro stage-specific chondrogenesis of mesenchymal stem cells committed to chondrocytes. Arthritis Rheum 60: 450-459.

Cook SD, Patron LP, Salkeld SL, Rueger DC (2003) Repair of articular cartilage defects with osteogenic protein-1 (BMP-7) in dogs. J Bone Joint Surg Am 85-A Suppl 3: 116-123.

Darling EM, Athanasiou KA (2003) Articular cartilage bioreactors and bioprocesses. Tissue Eng 9: 9-26.

De Bari C, Dell'Accio F, Tylzanowski P, Luyten FP (2001) Multipotent mesenchymal stem cells from adult human synovial membrane. Arthritis Rheum 44: 19281942.

Djouad F, Delorme B, Maurice M, Bony C, Apparailly F, Louis-Plence P, Canovas F, Charbord P, Noel D, Jorgensen C (2007) Microenvironmental changes during differentiation of mesenchymal stem cells towards chondrocytes. Arthritis Res Ther 9: R33.

Fan J, Varshney RR, Ren L, Cai D, Wang DA (2009) Synovium-derived mesenchymal stem cells: a new cell source for musculoskeletal regeneration. Tissue Eng Part B Rev 15: 75-86.

Freed LE, Grande DA, Lingbin Z, Emmanual J, Marquis JC, Langer R (1994) Joint resurfacing using allograft chondrocytes and synthetic biodegradable polymer scaffolds. J Biomed Mater Res 28: 891-899.

Frenkel SR, Di Cesare PE (1999) Degradation and repair of articular cartilage. Front Biosci 4: D671-685.

Furukawa KS, Suenaga H, Toita K, Numata A, Tanaka J, Ushida T, Sakai Y, Tateishi T (2003) Rapid and largescale formation of chondrocyte aggregates by rotational culture. Cell Transplant 12: 475-479.

Gigout A, Buschmann MD, Jolicoeur M (2009) Chondrocytes cultured in stirred suspension with serum-free medium containing pluronic-68 aggregate and proliferate while maintaining their differentiated phenotype. Tissue Eng Part A 15: 2237-2248.

Grassel S, Ahmed N (2007) Influence of cellular microenvironment and paracrine signals on chondrogenic differentiation. Front Biosci 12: 4946-4956.

Iwasa J, Engebretsen L, Shima Y, Ochi M (2009) Clinical application of scaffolds for cartilage tissue engineering. Knee Surg Sports Traumatol Arthrosc 17:561577.

Kaneshiro N, Sato M, Ishihara M, Mitani G, Sakai H, Mochida J (2006) Bioengineered chondrocyte sheets may be potentially useful for the treatment of partial thickness defects of articular cartilage. Biochemical and biophysical research communications 349: 723-731. 
Koga H, Muneta T, Ju YJ, Nagase T, Nimura A, Mochizuki T, Ichinose S, von der Mark K, Sekiya I (2007) Synovial stem cells are regionally specified according to local microenvironments after implantation for cartilage regeneration. Stem Cells 25: 689-696.

Koga H, Muneta T, Nagase T, Nimura A, Ju YJ, Mochizuki T, Sekiya I (2008a) Comparison of mesenchymal tissues-derived stem cells for in vivo chondrogenesis: suitable conditions for cell therapy of cartilage defects in rabbit. Cell and tissue research 333: 207-215.

Koga H, Shimaya M, Muneta T, Nimura A, Morito T, Hayashi M, Suzuki S, Ju YJ, Mochizuki T, Sekiya I (2008b) Local adherent technique for transplanting mesenchymal stem cells as a potential treatment of cartilage defect. Arthritis Res Ther 10: R84.

Lee JI (2007) Transplants encapsulated with eelfelastic cartilage and method of preparing the same. WO 2008/002059. World Intellectual Property Organization International Bureau, International application published under the Patent Cooperation Treaty (PCT).

Lin Z, Willers C, Xu J, Zheng MH (2006) The chondrocyte: biology and clinical application. Tissue Eng 12: 1971-1984.

Masuoka K, Asazuma T, Ishihara M, Sato M, Hattori H, Yoshihara Y, Matsui T, Takase B, Kikuchi M, Nemoto $\mathrm{K}$ (2005) Tissue engineering of articular cartilage using an allograft of cultured chondrocytes in a membrane-sealed atelocollagen honeycomb-shaped scaffold (ACHMS scaffold). J Biomed Mater Res B Appl Biomater 75: 177 184.

Mitani G, Sato M, Lee JI, Kaneshiro N, Ishihara M, Ota N, Kokubo M, Sakai H, Kikuchi T, Mochida J (2009) The properties of bioengineered chondrocyte sheets for cartilage regeneration. BMC Biotechnol 9: 17.

Mochizuki T, Muneta T, Sakaguchi Y, Nimura A, Yokoyama A, Koga H, Sekiya I (2006) Higher chondrogenic potential of fibrous synovium- and adipose synovium-derived cells compared with subcutaneous fatderived cells: distinguishing properties of mesenchymal stem cells in humans. Arthritis Rheum 54: 843-853.

Nagai T, Furukawa KS, Sato M, Ushida T, Mochida J (2008a) Characteristics of a scaffold-free articular chondrocyte plate grown in rotational culture. Tissue Eng Part A14: 1183-1193

Nagai T, Sato M, Furukawa KS, Kutsuna T, Ohta N, Ushida T, Mochida J (2008b) Optimization of allograft implantation using scaffold-free chondrocyte plates. Tissue Eng Part A 14: 1225-1235.

Nagase T, Muneta T, Ju YJ, Hara K, Morito T, Koga H, Nimura A, Mochizuki T, Sekiya I (2008) Analysis of the chondrogenic potential of human synovial stem cells according to harvest site and culture parameters in knees with medial compartment osteoarthritis. Arthritis Rheum 58: 1389-1398.

Nehrer S, Domayer S, Dorotka R, Schatz K, Bindreiter U, Kotz R (2006) Three-year clinical outcome after chondrocyte transplantation using a hyaluronan matrix for cartilage repair. Eur J Radiol 57: 3-8.

Nimura A, Muneta T, Koga H, Mochizuki T, Suzuki K, Makino H, Umezawa A, Sekiya I (2008) Increased proliferation of human synovial mesenchymal stem cells with autologous human serum: comparisons with bone marrow mesenchymal stem cells and with fetal bovine serum. Arthritis Rheum 58: 501-510.

Ochi M, Uchio Y, Kawasaki K, Wakitani S, Iwasa J (2002) Transplantation of cartilage-like tissue made by tissue engineering in the treatment of cartilage defects of the knee. J Bone Joint Surg Br 84: 571-578.

Ochi M, Uchio Y, Tobita M, Kuriwaka M (2001) Current concepts in tissue engineering technique for repair of cartilage defect. Artif Organs 25: 172-179.

Pittenger MF, Mackay AM, Beck SC, Jaiswal RK, Douglas R, Mosca JD, Moorman MA, Simonetti DW, Craig S, Marshak DR (1999) Multilineage potential of adult human mesenchymal stem cells. Science 284: 143-147.

Prockop DJ (1997) Marrow stromal cells as stem cells for nonhematopoietic tissues. Science 276: 71-74.

Quintana L, zur Nieden NI, Semino CE (2009) Morphogenetic and regulatory mechanisms during developmental chondrogenesis: new paradigms for cartilage tissue engineering. Tissue Eng Part B Rev 15: 29-41.

Sakaguchi Y, Sekiya I, Yagishita K, Muneta T (2005) Comparison of human stem cells derived from various mesenchymal tissues: superiority of synovium as a cell source. Arthritis Rheum 52: 2521-2529.

Samlowski WE, Robertson BA, Draper BK, Prystas E, McGregor JR (1991) Effects of supravital fluorochromes used to analyze the in vivo homing of murine lymphocytes on cellular function. J Immunol Methods 144: 101-115.

Sekiya I, Larson BL, Smith JR, Pochampally R, Cui JG, Prockop DJ (2002) Expansion of human adult stem cells from bone marrow stroma: conditions that maximize the yields of early progenitors and evaluate their quality. Stem Cells 20: 530-541.

Shimaya M, Muneta T, Ichinose S, Tsuji K, Sekiya I (2010) Magnesium enhances adherence and cartilage formation of synovial mesenchymal stem cells through integrins. Osteoarthritis and cartilage / OARS, Osteoarthritis Res Soc 18: 1300-1309.

Shimomura K, Ando W, Tateishi K, Nansai R, Fujie H, Hart DA, Kohda H, Kita K, Kanamoto T, Mae T, Nakata K, Shino K, Yoshikawa H, Nakamura N (2010) The influence of skeletal maturity on allogenic synovial mesenchymal stem cell-based repair of cartilage in a large animal model. Biomaterials 31: 8004-8011.

Wakitani S, Imoto K, Yamamoto T, Saito M, Murata N, Yoneda M (2002) Human autologous culture expanded bone marrow mesenchymal cell transplantation for repair of cartilage defects in osteoarthritic knees. Osteoarthritis Cartilage 10: 199-206.

Watt FM (1988) Effect of seeding density on stability of the differentiated phenotype of pig articular chondrocytes in culture. J Cell Sci 89: 373-378.

Yoshimura H, Muneta T, Nimura A, Yokoyama A, Koga H, Sekiya I (2007) Comparison of rat mesenchymal stem cells derived from bone marrow, synovium, periosteum, adipose tissue, and muscle. Cell Tissue Res 327: 449-462.

Zhang Z, McCaffery JM, Spencer RG, Francomano CA (2004) Hyaline cartilage engineered by chondrocytes 
in pellet culture: histological, immunohistochemical and ultrastructural analysis in comparison with cartilage explants. J Anat 205: 229-237.

\section{Discussion with Reviewers}

Reviewer I: The results showed that there was no noticeable difference in the chondrogenic matrix synthesis in any $\mathrm{AC} / \mathrm{SY}$ combination and that the matrix formed was not particularly chondrogenic. Please comment.

Authors: As there was no noticeable difference in the synthesis of the chondrogenic matrix in any AC/SY combination in the present study, we chose an SY:AC ratio of 75:25 for spheroids based on the utility of SYs as a partial replacement for ACs. This formation maximised the merit and efficacy of using SYs of high proliferation with less invasive procedure and donor site morbidity among other cellular ratios using SYs based on quantity of tissue demanded. In this study, the matrix formed did not seem particularly chondrogenic in the in vitro condition; however, our scaffold-free spheroids were confirmed as being an immature state of cartilage grafts, which are expected to regenerate into normal cartilaginous tissue in situ and in vivo.

Reviewer I: Has any type of X immunofluorescence been carried out?

Authors: In this study, we have not performed immunohistochemistry for type $X$ collagen in the spheroids that are associated with chondrocyte hypertrophy and matrix mineralisation. However, we think that this immunohistochemistry is worth performing to obtain precise information on the state of spheroids regardless of the duration of the in vitro culturing of cartilaginous tissue.
Reviewer I: Does the PKH26 remain evident in the processed samples? If so, could you use this to detect which cells have contributed to repair or could another marker be used that will allow the cells to be tracked during defect repair? This would also show if cells have migrated from the bone marrow as the defect penetrated the sub-chondral bone.

Authors: Yes, obviously the PKH fluorescent cell linker dye remained in the processed samples for in vitro evaluation of the morphology and distribution of cells within the spheroids of mixed ACs and SYs. However, we have not performed in vivo tracing using this fluorescent dye, as mentioned previously. In addition, similarly, we could use a specific marker that allows the tracking of cells that migrated from the bone marrow during the repair of the defect. However, we have not performed this experiment either. Further experiments regarding this curiosity will be expected to reveal the exact mechanism involving ACs, SYs and cells from bone marrow that represents the complicated phenomenon of cartilage regeneration.

Reviewer I: If the spheroids were kept in culture for a longer time period, are any differences seen in matrix production between the different ratios of AC/SY cells?

Authors: In this study, we did not perform long-term culture (over 3 days) with the spheroids kept in the HDSS culture system. However, we expect chondrogenesis of spheroids in the 3D HDSS culture condition with an extended culturing period (over 2-3 weeks) (Zhang et al., 2004, text reference). Our culture system yields a similar state of 3D culture, such as pellet culture, but this system gives rise additionally to shearing stress generated by the circular flow of the culture medium. Therefore, we expect that our system differs from ordinary 3D cultures. Additional comparative studies between our method and conventional 3D culture methods are needed to establish the differences, and such studies are being carried out at present. 